\title{
Los recursos fotográficos en los periódicos digitales: valores de la fotografía digital
}

Photographic resources in digital newspapers: the values of digital photography

Juan Miguel Sánchez Vigil (1), Juan Carlos Marcos Recio (2) y Ricardo Villegas Tovar (3)

(1) Biblioteconomía y Documentación, Adv. Ciudad Universitaria S/N, Universidad Complutense, jmvigil@terra.es, (2) jmarcos@ccinf.ucm.es, (3) Biblioteca “Niels Bohr”, Ciudad Universitaria, Benemérita Universidad Autónoma de Puebla, Puebla, México. ricardo.villegas@dgb.buap.mx

\begin{abstract}
Resumen
La fotografía digital en su aplicación a los medios de comunicación y concretamente a la prensa tiene unas características especiales. Su circulación fluida en la red, su disponibilidad y en especial su formato, que no ha imprescindible la excelencia en la calidad, para ser reproducida, plantean cuestiones de gran interés que aun no han sido analizadas en profundidad. La proliferación de sitios web en los que se invita a los aficionados (también a profesionales) a que depositen sus fotos, libres de derechos, y en consecuencia para cualquier uso, está planteando serios problemas a las empresas de creación y comercialización de imágenes, incluso a las grandes agencias de información. Los impactos de la fotografía digital en la prensa (inmediatez, análisis y almacenamiento) son tan extraordinarios que generan debates continuos entre los profesionales. Por lo que respecta a la aplicación, se realizan en este trabajo análisis tomando como referencia los principales diarios españoles, teniendo en cuenta la cantidad y tipología de las imágenes, las secciones ilustradas, el diseño de página y otras cuestiones que se han considerado fundamentales.
\end{abstract}

Palabras clave: Fotografía. Fotografía digital. Periódicos digitales. Prensa digital.

\section{Introducción}

La foto digital, al igual que la analógica, se capta en el momento, si bien permite la manipulación inmediata. Si con los procesos tradicionales debíamos esperar a que la imagen apareciera por arte de magia tras un proceso químico, ahora el autor de la imagen es el que la controla, seleccionando en la propia cámara el encuadre, o bien anulando la imagen en el momento para su repetición.

La tecnología actual permite realizar varios disparos con las cámaras de motor, generando numerosos documentos prácticamente iguales de los que finalmente se selecciona uno. En

\begin{abstract}
Digital photography when applied to the communications media and in particular to the written press takes on certain specific characteristics. Its fluid circulation on the net, its availability and in particular its format, which does not necessarily demand excellent, flawless quality in order to be reproduced, raises certain questions of great interest which have still not been analysed in depth. The large number of web sites which invite amateurs (as well as professionals) to post their photographs, free of all rights, thus making them available for any use whatsoever, raises serious problems for the companies engaged in the creation and marketing of images, as well as for the leading information and news agencies. The impact of digital photography on the press (immediacy, analysis, stockpiling and collection) are so extraordinary that they stir up continuous controversy among professionals. As regards their application, an analysis is made in this study, using the leading Spanish daily newspapers as the references, bearing in mind their quantity, types of images, illustrated sections, page design and other factors which have been considered fundamental.
\end{abstract}

Keywords: Photography. Digital photography. Digital newspapers. Digital press.

relación con este tema he de señalar que la mayoría de los usuarios de cámaras digitales (aficionados y profesionales) eliminan a diario millones de documentos, muchos más de los que generan. Denominaremos a estos documentos "fotografías digitales efímeras"; es decir, fotografías que existieron para no ser vistas.

La fotografía digital es aplicada inmediatamente a los medios. En apenas dos minutos colgamos en la red la toma, de forma que los portales especializados disponen de la imagen o de la galería de imágenes casi en tiempo real. Ahora bien, en relación a la inmediatez cabe preguntarse si es correcto el borrado de imágenes con tan solo contemplar la pantalla de la cámara 
donde no es posible visualizar todos los detalles de la información. En la foto analógica descubrimos cada día información que en su momento no fue relevante y que en la recuperación resulta de gran interés. Los fondos de la agencia EFE son un ejemplo, donde el equipo de documentación recupera actualmente imágenes históricas en series de negativos que no fueron destruidos por el hecho de ser parecidos.

La foto digital se genera con datos que los propios programas de la cámara asignan: códigos de identificación, formato, peso de la imagen, diafragma, velocidad, etc. Con los soportes tradicionales (negativos) era necesario generar copias en papel para su estudio, ya que la dificultad de analizar negativos es evidente por sus propias características. Hemos de tener en cuenta que la mayoría de los archivos y centros de documentación disponen de dos colecciones del mismo tema en doble soporte: negativo y papel.

Para el tratamiento y análisis de fotografías digitales se han generado programas informáticos que analizan contenido y continente. Los últimos trabajos de investigación plantean la recuperación incluso por los colores de la imagen. En este sentido se avanza con gran rapidez, pero se plantea sin embargo una cuestión importante: ¿qué hacer con las fotos analógicas cuya transformación a digital se hace imprescindible para no perder la memoria histórica? Bill Gates, propietario de la agencia Corbis, una de las más prestigiosas del mundo, llegó a comprar una mina en Minesota con la idea de hacer una especie de Imaginarium en el que recopilar, tratar y conservar documentos gráficos. Compró numerosos archivos importantes, invirtió cantidades ingentes de dinero y contrató a personal especializado, pero el resultado no fue satisfactorio, porque un estudio del proyecto dio como resultado que tan solo en escanear el material adquirido se tardaría decenas de años.

Es fundamental trabajar en una línea común para diseñar un programa común, y naturalmente protocolos de actuación conjunta, al igual que se han desarrollado en otros campos. Es esta una cuestión que parece no interesar a los grandes medios, ya que cada uno ha desarrollado su propio sistema, ignorando el de la competencia. Siguiendo con el modelo de la agencia EFE, el servicio de Documentación desarrolló su propio tesauro y diseñó los campos de trabajo atendiendo a sus necesidades. El sistema es el adecuado para sus funciones, pero no es compatible con los de otras agencias, aun siendo las pretensiones iguales.
Gracias a la fotografía digital se han creado nuevas asociaciones como la EPA (European Press Agency), una agencia distribuidora que agrupa a los principales centros públicos de Europa, y cuya función es competir con las grandes agencias estadounidenses y principalmente con AP. En realidad esta agencia no cuenta con fondos sino que se nutre de los fondos de las agencias que la compone gracias a su condición digital. Distribuye material de toda Europa canalizado desde su sede central en Francfurt (Alemania).

Por lo que respecta al almacenamiento, es este uno de los puntos en el que la foto digital ha resultado decisiva para su propia evolución. El problema mayor de todos los centros de documentación es el precio del espacio. Los archivos tradicionales requerían de mucho espacio, mientras que los ficheros digitales se almacenan en servidores de tamaño reducido, si bien las copias de seguridad, dado el volumen de material que se genera, invaden rápidamente el espacio reservado para otras tareas. En la sede central de la agencia EFE (Madrid), se seleccionan a diario más de un millar de fotografías por el departamento de documentación, que se conservan en DVD. Pues bien, en los últimos dos años el espacio consumido, no siendo comparable al de la foto en papel, es uno de los problemas a solventar. El almacenamiento se realiza en discos, con copias de seguridad que deben ser revisadas paulatinamente, porque la garantía de los soportes se cuestiona. Este sistema obliga a realizar fuertes inversiones en soportes para copiado, bajo la responsabilidad de expertos en tales cuestiones, y, por supuesto, a una constante revisión de los fondos. Todavía hoy se desconoce el impacto de la humedad y la luz sobre CDs y DVDs. La pérdida de un rollo de negativos supone eliminar 36 imágenes, mientras que en un DVD pueden destruirse más de un millar de imágenes sobre contenidos diferentes.

Una cuestión más sobre este aspecto. El peso de las imágenes en el servidor bloquea en ocasiones la respuesta a la demanda de información y la respuesta no es inmediata. Las pruebas de fluidez resultan extraordinarias cuando las materias son específicas; es decir, cuando se realiza una búsqueda muy concreta. Sin embargo, la respuesta a temas generales no solo no es inmediata sino que es muy lenta cuando se trata de temas generales a supervisar. De nuevo, el ejemplo es el fondo de EFE, donde al plantear búsquedas sobre la Segunda Guerra Mundial el resultado fue lento y con mucho "ruido". 


\section{La fotografía en la prensa digital. Consideraciones}

En el año 2000 las imágenes reproducidas en la prensa en papel eran las mismas que en las ediciones digitales (Caminos Marcet, 2006, p. 10). El uso de las fotografías era fundamentalmente complementario, si bien la fase experimental justificaba tal utilización. Pero además de esta consideración hay un aspecto fundamental a tener en cuenta en la aplicación de las imágenes digitales: las dimensiones de la pantalla del ordenador, porque las 17 pulgada comunes equivalen a un DIN A-4 y reducen las fotografías a mínimos. Se pierden, por consiguiente, los detalles en planos generales. Ahora bien, al no necesitar imágenes con alta resolución, pueden fragmentarse las tomas para recurrir al detalle. Las galerías de las páginas web y de los portales son un ejemplo. Para ofrecer imágenes de mayor tamaño y calidad, las empresas recurrieron a las galerías, donde se agrupa una selección de los mejores temas. Sin embargo, al quedar fuera de contexto no forman parte de la información sino que se aislan. Esto permite una valoración de la imagen en sí misma y un análisis sobre los criterios de selección. Por otra parte, hay un aspecto paralelo: la comercialización, ya que las galerías son una especia de catálogo o muestrario desde el que se ofertan los fondos de los diarios.

\section{Objeto}

El objetivo ha sido analizar la documentación fotográfica de distintos periódicos digitales durante un periodo de tiempo determinado. Para elaborar el estudio se han analizado cuatro diarios de tirada nacional: El País, El Mundo, La Vanguardia y $A B C$. Durante diez semanas (dos meses y medio) se ha estudiado el tratamiento documental de las fotografías publicadas en los periódicos en diferentes días de la semana, extrayendo datos referentes a secciones, número de fotos por sección, número de retratos por sección, idoneidad de las imágenes -fotos idóneas al contenido de la noticia, fotos no idóneas al contenido de la noticia-, galería de fotos, sección o secciones aparecidas en la galería de fotos del día, número de fotos de una sección que forman parte de la galería del día, número de retratos de una sección que forman parte de la galería del día, relación de fotógrafos, listado de los fotógrafos que han publicado alguna fotografía en el periódico el día que hemos elaborado nuestra investigación, relación de agencias - listado de agencias fotográficas de las cuales el periódico ha tomado alguna fotografía el día de la investigación-, y número de fotos con pie de autor — total de fotografías aparecidas en el periódico estudiado que son acompañadas de un pie de autor o agencia.

\section{Metodología}

El estudio se realizó en dos partes de las que se obtienen las conclusiones finales. En la primera parte nos dedicamos a la realización de las tablas con los datos sobre las fotografías que vamos obteniendo en el análisis del periódico en su correspondiente día. Recogemos información acerca de las secciones, idoneidad de las imágenes, galería de fotos, fotógrafos y agencias de fotografía. La segunda parte consiste en la elaboración de las estadísticas y gráficos a partir de los datos obtenidos durante la observación y tratamiento de la información recogida de los distintos diarios digitales.

\section{Resultados obtenidos}

Se presentan los resultados tras el análisis, teniendo en cuenta la ratio de fotos por periódico, la autoría, el porcentaje de retratos, los autores y agencias, la idoneidad y las galerías seleccionadas.

\subsection{Fotografías por periódico}

\subsubsection{Ratio de fotografías por periódico}

En el gráfico 1 podemos observar como ABC y La Vanguardia con un $36,08 \%$ y un $33,91 \%$ doblan en porcentaje de número de fotografías introducidas por periódico a los diarios El País y El Mundo que apenas llegan al 15,52\% y $14,49 \%$ respectivamente.

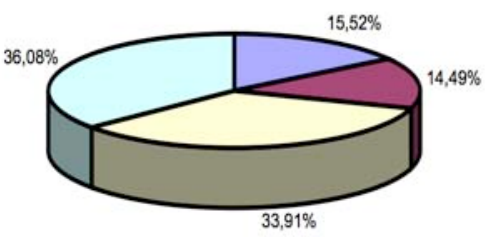

口El Pais aEl Mundo $\square$ La Vanguardia $\square A B C$

Gráfico 1. Ratio de fotografías por periódico.

\subsubsection{Autoría de las fotografías}

En el dibujo se advierte la tendencia de los cuatro periódicos a trabajar con fotografías proporcionadas por agencia con una diferencia aproximada del $69 \%$ respecto a las fotografías donde la autoría corresponde a un fotógrafo del periódico. Además, comprobamos la existencia de un $7,52 \%$ de las fotografías que carecen de un pie de foto que nos indique quien es el creador de la imagen. 


\subsubsection{Porcentaje de retratos por periódico}

Los diarios $A B C$ y La Vanguardia (gráfico 2) encabezan esta estadística sobre las imágenes que son retratos con un $58,99 \%$ y un $54,46 \%$ respectivamente. El País y El Mundo se sitúan en $47,98 \%$ y un $44,30 \%$ por lo que las diferencias entre los cuatro periódicos se localizan en un intervalo del $14,69 \%$ la mayor diferencia y un $6,48 \%$ la menor diferencia.

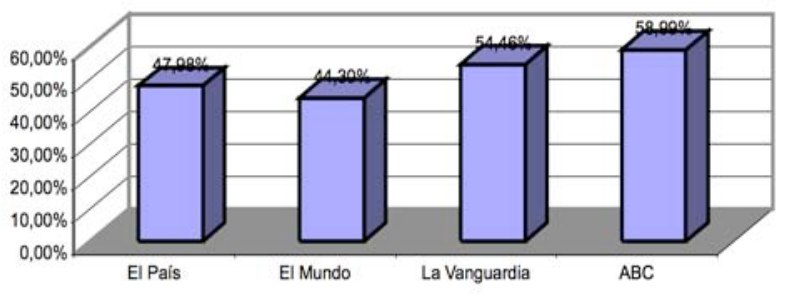

Gráfico 2. Porcentaje de retratos por periódico.

\subsubsection{Fotógrafos que aparecen en los periódicos}

Sin duda alguna este gráfico nos aporta un dato interesante pues evidencia que el periódico La Vanguardia con un $59 \%$ del total es el diario que mas fotógrafos requiere para sus noticias, mientras $\mathrm{ABC}$ con un $5 \%$ es el que menor número de fotografías proporcionadas por sus fotógrafos edita en la versión electrónica del diario. Estos datos permiten comprobar que entre los periódicos de mayor ratio de fotografías existe una gran diferencia en el número de fotografías que son de fotógrafo y las que son de agencia. Por su parte, El País se aposta en un segundo lugar con un $26 \%$ y El Mundo el tercero con un $10 \%$ del total respectivamente.

\subsubsection{Porcentaje de idoneidad de las fotografías}

El gráfico 3 de barras presenta al $A B C$ como el diario de mayor porcentaje de idoneidad entre el contenido de la noticia y la imagen que la ilustra con un $50,61 \%$ y a La Vanguardia con un $48,97 \%$ en un segundo lugar. El País y El Mundo vuelven a ocupar los dos últimos lugares de la estadística con unos discretos $30,43 \%$ y $29,70 \%$ respectivamente. Estos resultados nos permiten reflexionar acerca del alto porcentaje de fotografías no adecuadas al contenido del artículo que cada periódico incluye en sus ediciones y que posteriormente en las conclusiones volveremos a mencionar.

\subsubsection{Agencias que aparecen en los periódicos}

Este apartado dedicado a medir la aportación de las agencias como fuente de documentación fotográfica podemos ver que, a excepción del periódico $A B C(6 \%)$, los otros tres periódicos (EI Mundo $33 \%$, El País $31 \%$ y La Vanguardia $30 \%$ ) sí complementan sus fotografías publicadas con aquellas que provienen de agencias en un porcentaje elevado.

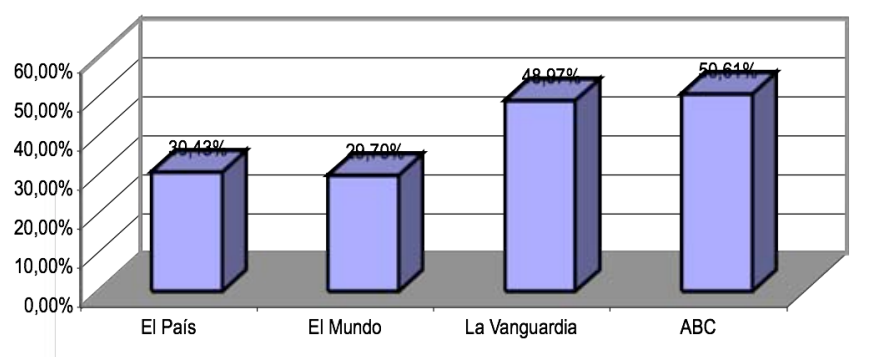

Gráfico 3. Porcentaje de idoneidad de las fotografías.

5.1.7. Porcentaje de retratos en las galerías de fotos por periódico

El diagrama de barras de este apartado estudiado ofrece un resultado bastante homogéneo en su parte superior, con El País en un porcentaje del $74,60 \%$ seguido de La Vanguardia con un $69,74 \%$. Por tanto podemos deducir que en sus galerías diarias predominan imágenes en primer plano de los acontecimientos o personas destacables en las noticias del día. El diario $A B C$ con un $59,26 \%$ y El Mundo con un $47,62 \%$ se emplazan en un tercer y cuarto lugar respectivamente.

\subsubsection{Ratios de fotografías en las galerías de foto por periódico}

En las ratios (gráfico 4) comprobamos como el periódico El País con un 40,65\% se ubica con el porcentaje diferencian ampliamente de La Vanguardia y $A B C$ que tan solo consiguen llegar al $17,39 \%$ y $4,06 \%$ respectivamente, por lo que la diferencia de porcentajes es bastante importante.
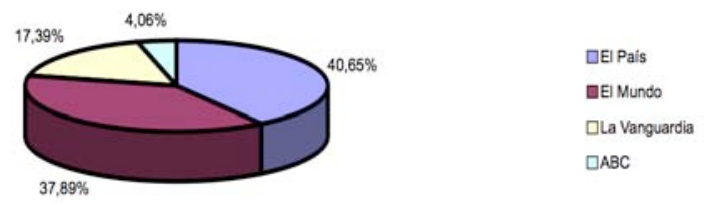

Gráfico 4. Fotografías en las galerías por periódicos.

\subsection{Secciones de los periódicos}

\subsubsection{Secciones de El País}

El gráfico 5 de barras que muestra la distribución de las fotografías del diario El País a lo largo del periodo estudiado nos ha dejado los siguientes resultados: respecto al número de fotos por sec- 
ción, en el diario El País la sección que mas número de fotos proporciona al total es su página de inicio, que, además, es la única que pasa de una aportación superior a 100 fotografías (149 para ser exactos). Le sigue un segundo grupo que alcanza un número de fotos superior a 70 fotografías y que esta compuesto por las secciones de Gente y TV (con 75 fotografías) e Internacional (con 73 fotografías). A continuación encontramos un tercer grupo con un número de fotografías superior o igual a 60 que esta integrado por la sección España (con 66 fotografías), Deportes (con 61 fotografías) y Cultura (con 60 fotografías). El cuarto y último grupo, comprendido por aquellas secciones que superan las 50 fotos, es el formado por las secciones de Sociedad (con 56 fotografías), Tecnología (con 55 fotografías) y Economía (con 54 fotografías). Para finalizar, la sección Opinión queda en último lugar con tan solo 18 fotografías.

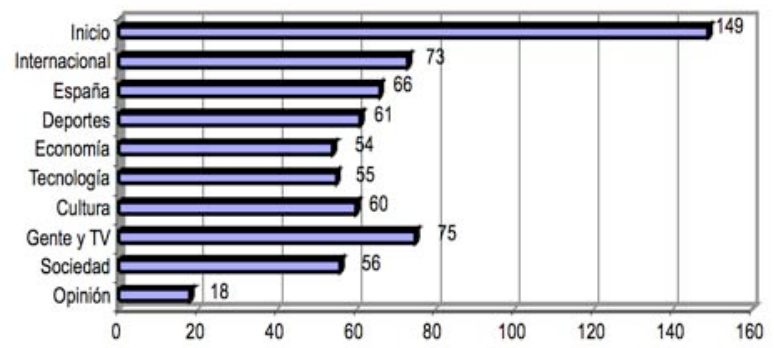

Gráfico 5. Secciones de El País.

\subsubsection{Secciones de la galería de fotos de El País}

Como se puede comprobar (gráfico 6) observando el resultado alcanzado, el diario El País no realiza una división por secciones de la galería de fotos, sino que incluye todas las fotos que le van llegando en un solo apartado al que llaman Últimas Fotos.

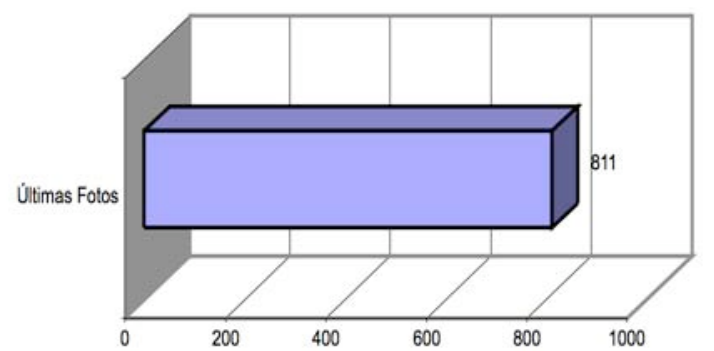

Gráfico 6. Secciones de la galería de fotos de El País.

Esta forma de proceder nos ha limitado la posibilidad de obtener unas estadísticas que sean útiles para nuestro trabajo, ya que el dato obtenido tan solo nos dice el número total de fotos aparecidas durante los días en que estudiamos este diario.

\subsubsection{Secciones de El Mundo}

El gráfico 7 de barras que muestra la distribución de las fotografías del diario El Mundo a lo largo del periodo estudiado nos ha dejado los siguientes resultados: La sección con mayor número de fotos es, con diferencia, al igual que en el caso anterior, la página de inicio del periódico con 141 fotografías. En esta ocasión, encontramos una sección más que supera las 100 fotografías: Deportes, exactamente con 104. Tras estas dos secciones, se encuentran las que superan las 60 fotografías, que son Salud (con 69 fotografías) y Madrid24h (con 64 fotografías). El tercer grupo lo forman las secciones de Cultura (con 55 fotografías), Ciencia (con 52 fotografías) y España (con 51 fotografías). En los últimos grupos se sitúan las secciones de Internacional (con 46 fotografías), Comunicación (con 22 fotografías) y Tecnología (con 19 fotografías). Es destacable que una sección como Economía, que en el anterior periódico alcanzaba la cifra de 54 fotografías, en El Mundo no reciba ninguna imagen que acompañe a sus noticias, lo que permite hacerse una idea de lo diferente que puede ser el tratamiento documental-fotográfico de las noticias.

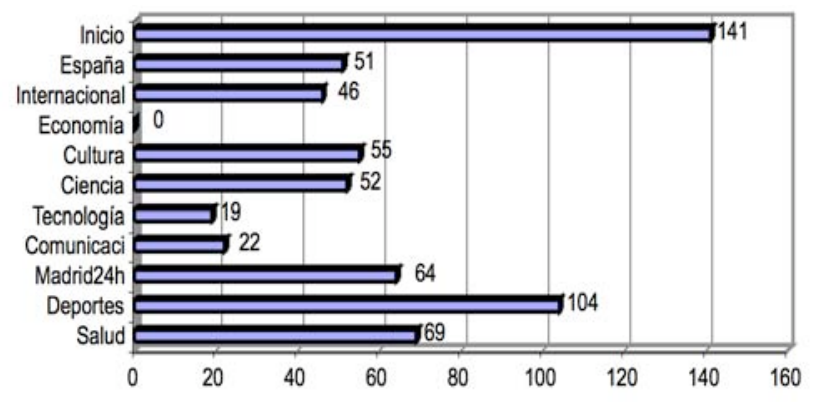

Gráfico 7. Secciones de El Mundo

\subsubsection{Secciones de la galería de fotos de El Mundo}

Los resultados (gráfico 8), extraídos del estudio de la galería de fotos del diario nos ofrecen una división de las secciones en cinco grupos: Actualidad, Gente, Deportes, Temas y Ciencia. De estos grupos Actualidad y Deportes son los únicos que superan las 200 fotografías, con 271 y 229 respectivamente. Actualidad es un grupo de composición muy diversa, pues incluye fotos de diferentes secciones como son España e Internacional, que pasan por ser dos de las secciones con mas fotografías del periódico; de ahí su alto número total. En tercer lugar esta la sec- 
ción Gente con 116 fotografías, único grupo, junto con los dos anteriores, que supera las 100 fotografías.

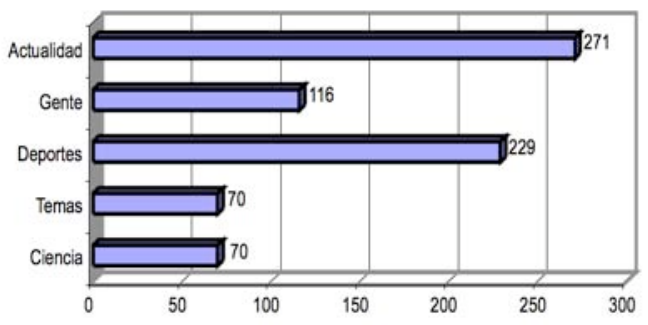

Gráfico 8. Secciones de la galería de fotos de El Mundo.

Para finalizar se encuentran los grupos de Temas y Ciencia que aportan 70 fotografías cada uno al total de la galería de fotografías del diario El Mundo. La sección Temas, al igual que pasa con Actualidad, incluye fotos de diferentes secciones que, al agruparse, constituyen un tema de actualidad (por ejemplo, en la sección Internacional, la galería de fotografías del nacimiento de la Infanta Sofía).

\subsubsection{Secciones de La Vanguardia}

El gráfico 9 de barras que muestra la distribución de las fotografías del diario La Vanguardia a lo largo del periodo estudiado nos ha dejado los siguientes resultados: De nuevo la sección con más fotografías es la página de inicio con 249 imágenes, lo que es lógico al ser la "carta de presentación" del diario al entrar en su web. En esta ocasión el número de secciones que superan las 100 fotografías es bastante alto, concretamente seis y se distribuye de la siguiente manera: Ciudadanos con 174 fotografías, Internacional con 171 fotografías, Cultura con 168 imágenes, Política con 151 imágenes, Gente con 132 retratos y Deportes con 122 retratos.

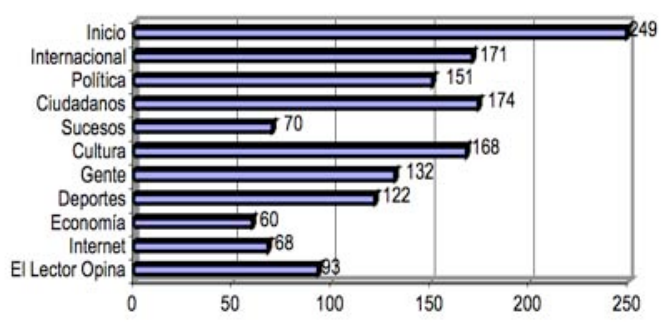

Gráfico 9. Secciones de la Vanguardia

A continuación se puede establecer un segundo grupo con aquellas secciones que no han superado las 100 fotografías y que estaría compren- dido por las secciones de El Lector Opina (con 93 fotografías), Sucesos (con 70 imágenes), Internet (con 68 retratos) y, en último lugar, Economía que presenta 60 fotografías tan solo.

\subsubsection{Secciones de la galería de fotos de La Vanguardia.}

A la vista de los resultados (gráfico 10), del trabajo realizado se comprueba, que el diario $\mathrm{La}$ Vanguardia divide su galería de fotos en las mismas secciones en las que su periódico se estructura; por lo que los resultados que obtenemos son bastante variados, puesto que hasta 8 secciones pasan de las 20 fotos totales, aunque ninguna supera las 100 , como si sucedía por ejemplo con El Mundo.

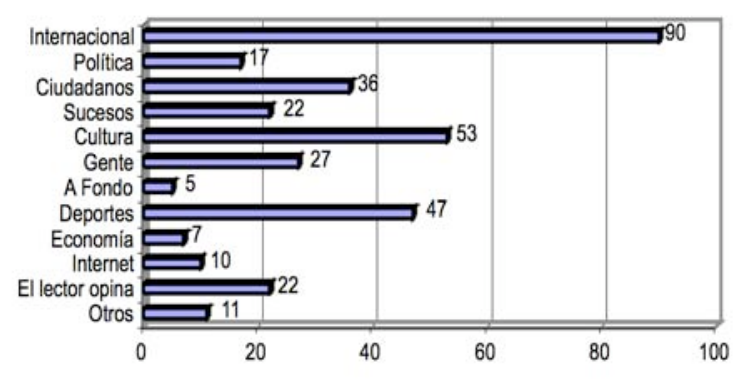

Gráfico 10. Secciones de la galería de fotos de La Vanguardia.

La sección que más fotografías proporciona es Internacional con 90 imágenes. Le siguen Cultura con 53 fotos y Deportes con 47 retratos. Con 36 fotos está el apartado Ciudadanos y con 27 imágenes la sección de Gente. Las secciones Sucesos y El Lector Opina son las últimas en superar la cifra de 20 fotos (en concreto 22 cada una) y cierran este grupo tan amplio.

A continuación, y ya con menos de 20 fotos, aparece la sección Política con 17 imágenes, seguida del apartado Otros con 11 fotografías e Internet con 10. Para finalizar, tan solo 2 secciones no superan las 10 fotografías y son Economía con 7 y A Fondo con 5 imágenes.

\subsubsection{Secciones de $A B C$}

El gráfico 11 de barras, que muestra la distribución de las fotografías del diario El Mundo a lo largo del periodo estudiado, nos ha dejado los siguientes resultados. Al contrario de lo sucedido hasta este momento en los periódicos anteriores, $A B C$ no tiene a su página de inicio como la sección con más fotografías, sino que esta circunstancia la reserva para el apartado de Gente \& Ocio con 497 fotografías. Esto puede ser debido a que dicho apartado engloba 12 
secciones que aportan fotografías al total de las 497 y que le hacen ser, con diferencia, el apartado mas ilustrado del diario.

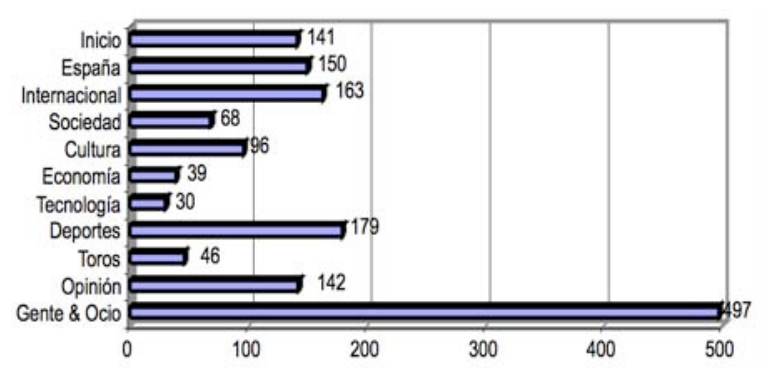

Gráfico 11. Secciones de $A B C$

Con más de 100 imágenes encontramos otras 5 secciones, que son: Deportes con 179 retratos, Internacional con 163 fotos; España con 150, Opinión con 142; y, por último, Inicio con 141 imágenes. Se puede ver como esta última sección, tan importante para los otros diarios, no ocupa una posición relevante en la clasificación que se obtiene de los resultados, lo que apunta que para $A B C$ otras secciones, como por ejemplo Deportes, merecen una mayor cantidad de fotografías que la página de inicio de su página web. Siguiendo la observación de los resultados encontramos un segundo grupo de secciones que no alcanzan las 100 fotografías y que se constituye de las secciones Cultura (con 96 imágenes), Sociedad (con 68 imágenes), Toros (con 46 fotos), Economía (con 39 retratos) y Tecnología (con 30 fotografías).

\subsubsection{Secciones de la galería de fotos de $A B C$}

Del estudio de las galerías de fotos de $A B C$ (gráfico 12) realizados a lo largo del periodo trabajado se han extraído cinco secciones que son las que mayor cantidad de fotos proporcionan al total. Es curioso observar como las secciones Gente \& Ocio y Deportes, las más ilustradas de todas las secciones del periódico, tan solo ocupan las últimas posiciones en este gráfico con una aportación prácticamente mínima (sobre todo, en el caso de Deportes, con 5 imágenes). Economía, con 16 fotos, es la tercera sección que mas fotografías ofrece, dato también curioso si se tiene en cuenta que en el gráfico del anterior apartado se encontraba en la penúltima posición respecto a la distribución de las ilustraciones por parte de $A B C$. Para finalizar, en lo alto del gráfico encontramos las secciones de Sociedad con 21 imágenes e Internacional con 27 fotografías aportadas a la galería de fotos de $A B C$ a lo largo del periodo estudiado.

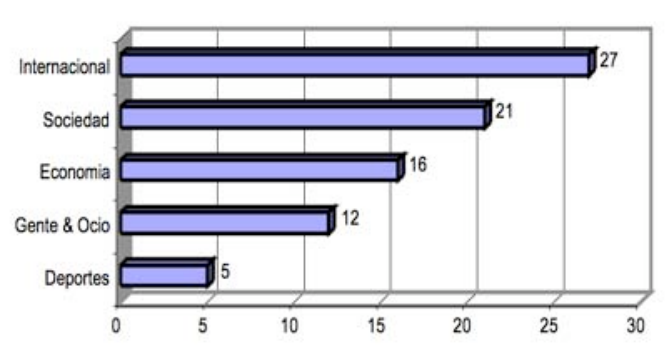

Gráfico 12. Secciones de la galería de fotos de $A B C$

\section{Conclusiones}

A partir de los resultados de la investigación, se puede concluir lo siguiente.

De todos los periódicos estudiados un par de ellos son considerados, tanto por la prensa como por los lectores, como dos de los diarios de mayor relevancia y tirada de España (El País y El Mundo). Por esta circunstancia, es destacable que ambos diarios ocupen las últimas posiciones en lo que se refiere a la clasificación de fotografías por periódico, ya que lo lógico sería que por los medios humanos, económicos y técnicos que se les suponen ocuparan las dos primeras plazas del gráfico relegando a los otros dos periódicos a las posiciones que ellos ocupan. Por tanto podemos concluir que en principio parece que el diario $A B C$ y La Vanguardia ilustran con mayor cantidad de imágenes sus ediciones electrónicas que El País y El Mundo (periódicos líderes en visitas a sus formatos electrónicos) a pesar de que seguramente dispongan de medios inferiores a estos dos últimos periódicos.

En lo correspondiente a la autoría de las fotos hemos comprobado como la fotografía obtenida de agencia domina la estadística de forma clara, con más de un $75 \%$ del total. Este hecho, que sin duda corresponde al buen funcionamiento de estas agencias, al ahorro en personal y medios técnicos por parte del periódico, etc., esperamos que no repercuta en la perdida de información por parte de la fotografía, sobre todo, en lo que respecta a su autoría. En muchas ocasiones a lo largo del estudio hemos encontrado que efectivamente la imagen venía acompañada de su correspondiente pie de foto con el nombre de la agencia de la cual se obtuvo la foto, pero a su vez el nombre del fotógrafo que trabaja para la agencia se pierde, ya que no se ha considerado necesario indicarlo. Por tanto, estamos perdiendo una parte de la autoría de la foto, porque, aunque tenemos quien la proporcionó, perdemos la información de quien elaboro el disparo de la cámara. 
Se puede constatar a través del estudio realizado que casi todos los periódicos utilizan la fotografía tipo retrato como en la mitad de sus ilustraciones. $A B C$ y La Vanguardia emplean este tipo de fotografía en más de la mitad de sus ilustraciones, mientras que El País y El Mundo se acercan al $50 \%$. Esto nos indica que a pesar de la gran diferencia que hemos comprobado que existe entre estos diarios en lo que respecta al computo total de fotografías, en el caso de los retratos los cuatro equiparan su uso como tipo de foto para ilustrar noticias.

En lo que se refiere al número de fotografías provenientes de fotógrafos por periódico, es interesante advertir el caso de ABC. Este diario, que pasa por ser el que mayor número de fotos ha computado, en esta ocasión ocupa el último lugar de la estadística, por lo que podemos concluir que en su política editorial la fotografía recibida de agencias ocupa un lugar preferente a las tomadas por los fotógrafos. El caso de los periódicos El País y El Mundo es muy parecido, pues parece que a ambos les sale más económico el trabajo realizado por las agencias que el de sus propios fotógrafos. Al otro lado, está La Vanguardia, único periódico de los cuatro que prefiere las fotos tomadas por sus fotógrafos a las que les llegan de agencia y que, por tanto, prácticamente monopoliza esta estadística.

La idoneidad de las imágenes respecto a la noticia que acompañan es otra variable que no podemos dejar pasar por alto, pues hemos obtenido unos resultados que a la vista, parecen sorprendentes. En principio, solo un periódico $(A B C)$ alcanza el $50 \%$ de la idoneidad, aunque La Vanguardia no queda muy lejos de esta cifra. Los otros dos diarios restantes (El País y EI Mundo) están cerca de un pobre $30 \%$. Por tanto, se puede concluir que una gran mayoría de las fotografías de prensa que acompañan a las noticias no aportan ninguna información a ésta, ya que no tiene ninguna relación la imagen con el artículo.

Como decíamos anteriormente el menor empleo de las fotos tomadas por los fotógrafos de los periódicos impulsa el uso de las agencias como fuente para ilustrar las noticias; por tanto, esta estadística está muy repartida entre los cuatro. Además tras observar los resultados que hemos recogido se ve que la agencia que más fotografías aporta a los diarios es EFE, como era de esperar al tratarse de la principal agencia de fotografías de España y una de las importantes de Europa.
Respecto a las fotografías que estos diarios incluyen en sus galerías, podemos mencionar que todos utilizan muy equilibradamente la fotografía de tipo paisaje con la fotografía de tipo retrato. Aquí se da un caso interesante en el periódico El País, el cual no alcanza un porcentaje muy alto en el porcentaje de retratos por periódico y que, en cambio, en este apartado tiene el porcentaje mayor, con casi un $75 \%$ de las fotografías que aparecen en su galería. Esto nos indica en cierto modo que habitualmente los diarios varían bastante entre el contenido fotográfico de sus noticias y el contenido fotográfico que le dan a sus galerías.

En lo concerniente a la distribución de las fotografías por secciones - como era de esperar en la mayor parte de los periódicos estudiados-, la sección que mayor número de fotos contiene es Inicio, porque para algo es la portada del diario en Internet. Sorprende el caso de $A B C$, que relega esta posición a su sección Gente \& Ocio, aunque seguramente por la razón que antes mencionamos en el análisis de los resultados. Lógico nos parece también que secciones como Internacional, Nacional, Deportes, etc., arrojen unos datos tan amplios pues suelen ser apartados en los que la noticia viene acompañada de imagen. En esta apartado cabe destacar sobre el resto de diarios estudiados a La Vanguardia, el cual tiene una gran variedad de secciones que aportan un número muy homogéneo de fotografías tanto en el caso del diario en si como en el caso de la galería de imágenes.

Por último, nos gustaría reflejar una opinión que hemos ido construyendo a lo largo de la elaboración del estudio y que no es otra que la percepción de que La Vanguardia es con diferencia el diario de los 4 estudiados que mejor tratamiento de las imágenes realiza desde el punto de vista de su documentación (entendiendo aspectos como la autoría, redacción de pies de foto, etc.).

\section{Referencias}

Caminos Marcel, José María; Murillo, Flora María, Armentia Vizuete, José Ignacio (2006). El uso de la fotografía en los diarios digitales españoles. // Comunicación y Sociedad. 19:2 (2006) 9-38. 